\title{
Challenges Encountered by Teachers in Managing Inclusive Classrooms in Swaziland
}

\author{
S'lungile Thwala (PhD)
}

Lecturer, University of Swaziland, Department of Educational Foundations and Management, P/No. 4 Kwaluseni, M201

Email:sskthwala@uniswa.sz

\author{
Doi:10.5901/mjss.2015.v6n1p495
}

\begin{abstract}
The purpose of the study in which this paper is derived was to identify challenges encountered by teachers in managing inclusive classrooms in Swaziland. The literature review shed light on the various aspects of inclusive education from the classroom to the outside environment to the teachers involved in inclusive education. The study employed qualitative methods in which Focus Group Discussions were utilized and Thirty five $(N=35)$ teachers were purposively sampled from primary schools in the Manzini region. Results revealed that a majority of teachers were not trained on how to teach in an inclusive class. However, the literature indicates that with proper training and resources, inclusion can be a practical and effective learning environment. It can be concluded that mainstream teachers generally lacked confidence as they attempted to include students with disabilities into classes. The study recommends that The Ministry of Education should consider increasing the availability of special needs courses, workshops and conference for teachers in primary schools who are working with students with disabilities.
\end{abstract}

Keywords: Inclusion, Classroom, Inclusive Education, Special Education, Mainstream

\section{Introduction}

Despite many efforts being put forth for the successful implementation of inclusive education in primary schools in Swaziland there are still numerous challenges teachers face in the implementation of the programme. Many teachers find it difficult to implement inclusive education because of various reasons. Inclusive education is an effort to provide special services for exceptional children in the least restrictive environment (Ainscow and Ceasar, 2006). This suggests that the exceptional child will be placed with normal peers and will receive special services while enrolled in regular classes, not special classes (Kirk, Gallagher, Anastasiow, and Coleman, 2006). This is a provision that should help the child interact as much as possible with his or her normal peers. There are many factors that have led to the move of mainstreaming exceptional children. Some of these include the observation that many children were misclassified as mentally challenged when they were not, that many special classes showed few beneficial results and that those classes tended to be understood as classes for problem children instead of remedial centers (Kirk et al, 2006).

According to Landsberg (2011), inclusion is about developing inclusive community and education systems. It is based on the value systems that invite and celebrate differences and diversity arising from gender, nationality, race, language, socio economic background, cultural origin and level of academic achievement and disability. Ainscow (2002) concurs with Burden (2000) when he describes inclusion as a process in which schools, communities, local authorities and government strive to reduce barriers to participation and learning for all citizens. For Booth (2000) inclusion goes beyond the school and is concerned with reducing exclusion from cultures. This means valuing and treating with respect everyone in the school and community, which calls for having faith in each individual that one has the ability to contribute to the society.

The Ministry of Education and Training declared that all children in the country should be admitted to the nearest community schools to access education regardless of ability or disability. This appeared to be a major challenge to schools. They were not ready for this sudden increase in enrollment. It was doubtful that the teachers were prepared to accommodate children with challenges in the mainstream schools. Masuku (2010) observed that Swaziland is not ready for inclusive education because of the number of barriers among which are lack of trained personnel to manage inclusive classrooms, and lack of funds and instructional materials. It is therefore, from such a premise that the researcher found it imperative to investigate challenges encountered by teachers in managing inclusive classrooms in Swaziland. 


\section{Teachers Competencies}

Teacher competencies are a central feature of teaching and learning. They become more critical when we think of inclusion. In that regard, Swart and Pettipher (2007) consider educators to be a key force in determining the quality of inclusion. Therefore, it is without doubt that they can, if given support manage inclusive classrooms. Educators as key figures in the successful implementation of an inclusive education policy, their competencies in this field are of utmost importance. Furthermore, in the article "Teacher preparedness for inclusive education", Hay, Smit, and Paulsen (2001) emphasise that the effective implementation of the programme depends on the high quality of professional preparation of teachers in all levels to equip them for and update their knowledge in handling mixed ability groups. This is supported by Winter (2006) when he points out that those teachers who are willing to pursue their skills-development need to be trained in a range of issues so that their contributions could be of value. It also recommends that educators among others be competent in communication skills and multidisciplinary work, some essential knowledge of common disabilities, behavior management, the effects of poverty and social deprivation and the skills to identify all the above by means of assessment processes.

From the above discussion, one may conclude that the teachers' lack of competency in managing their inclusive classrooms is a serious problem as it makes them feel stressed and less confident. Other researchers (Broderick 2005, Ainscow 2009, and Landsburg 2011), have highlighted that it is not practically possible to make specialists of all educators on all the diverse needs in overcoming barriers to learning, but there may be a way of assisting all learners to benefit from inclusive classes, that is, by empowering teachers with basic skills so that they may become competent inclusive teachers. Van Zyl (2002) states that there are various skills that are important for a teacher to teach in an inclusive school. He calls for orientation on inclusive education and the paradigm shift from the medical model to a human rights model of learner with special educational needs. Other researchers proposed a Socio-ecological Model which developed as a critique to the medical deficit model whereby the learner's social context forms the core of accepting diversity and allowing the participation of individuals regardless of differences (Cesar and Ainscow 2006; Reindal 2008; Landsberg, Kruger and Swart 2011). The indication in the literature is that there has been a steady shift from the medical to the socio-ecological model.

On Van Zyl's point on collaborative teaching, the Draft Guidelines for Inclusive Learning Programmes (2005) in South Africa states that educators need to be trained to work with each other as well as with other professionals such as occupational therapists, physiotherapists, social workers, and other specialists for the benefit of the learners with barriers to learning in mainstream schools. It is therefore important for this study not to neglect collaborative teaching because that would limit the effectiveness of teaching and learning in the classroom. According to Landberg, Kruger and Neil (2006) special schools are based on a medical model (of diagnosis and treatment) which provides a special kind of education. It is highly focused on pathology, sickness, and dealing with specific pathology in a centred way.

\section{Methodology}

The research on which this article is based adopted a qualitative approach. Seven schools were purposefully selected in rural areas and eight schools in urban areas in Manzini Region. Focus group Interviews were used to collect data from the thirty five purposefully selected inclusive teachers from the selected schools. A Focus group Interview guide was used to ensure that all practitioners were asked the same open-ended questions and were therefore free to express their own opinions. Participants were asked to be honest about inclusive education. Their inputs about what they lack as educators, availability of facilities, their competencies in managing pupils with different disabilities, challenges encountered in the implementation of inclusion and different strategies that educators feel could be of value to promote the management of inclusive education. Qualitative data was analysed inductively using the constant comparative analyses (Merriam, 2002) where data was collected, transcribed, coded and categorized and themes emerged from the data.

\section{Results}

From the data gathered themes were identified as challenges encountered by teachers in managing inclusive classrooms namely; lack of teachers' training, lack of Competencies, lack of concrete materials, large classrooms, time allocation and assessment. All quotations in support of the themes were taken verbatim. 


\subsection{Theme 1: Lack of teachers' training}

In order to achieve professional skills one has to go via training. The majority of the participants showed that they are not trained in special education in preparation for inclusion in mainstream schools. But they think given an opportunity to practice the basic classroom management techniques, they can make it. One participant had this to say;

"I am not trained for inclusion", "I am not well versed about how to handle an inclusive classroom"," I have no knowledge of handling learners with disabilities", "Not an effective teacher."

This shows that in as much as the government of Swaziland wish to implement the programme, it is not possible if teachers are not trained. Some respondents stated that they have just enrolled at the University of South Africa (UNISA) specializing on inclusive education, at the University of Swaziland (UNISWA) on Special Education, and others said they are still training at the Southern African Nazarene University (SANU). Very few indicated that they have been trained for the new programme. Participants agreed that they had only attended workshops on inclusive education. However, they felt that the time allocated for workshops were insufficient because inclusive education is a new programme which needs intensive training. They emphasized that workshops should be on ongoing basis until educators feel that they are well equipped to teach inclusive classrooms effectively. In service training also goes a long way on the part of an inclusive curriculum. At colleges during training, inclusion was not part of their curriculum, thus they were never exposed to teaching learners with disabilities. This made them insecure and ineffective to their teaching, hence the need for in service training.

\subsection{Theme 2: Lack of Competencies}

One of the most important themes identified is the teacher competency. It was gathered that from the interview that participants cited a common factor called competencies they need as educators. They showed that inclusive education is stressful to them since they lack skills in dealing with disabilities. When asked if they are competent enough to teach in inclusive classrooms, most of their responses indicated "not at all." It goes back to training, if one is not knowledgeable and lacks skills, it becomes a problem. Hence lack of training in inclusion is a disaster to teachers or educators who teach in inclusive classrooms. Thus, the lack of training will impede the effective implementation of the programme.

\subsection{Theme 3: lack of concrete materials}

All participants said that in schools they lack proper teaching and learning materials that would help accommodate the learners with disabilities. Few participants stressed that learners need concrete materials that they can touch and feel if the learner is visually impaired. Moreover, the learner's thought processes depend on contact with concrete objects.

Another practitioner's remarks gave credence to the notion of full Inclusion when she stated;

"Unless the government of Swaziland has financial muscle to buy learning facilities like computers, tape recorders, Braille, hearing aids, overhead projectors, magnifying glasses to make letters large the issue of inclusion will always remain on paper"

Participants when asked if they are competent with these technological devices used for visually and hearing impaired learners gave a big " NO" as an answer. All of them mentioned that they only have theory about these devices; practically they have never touched these devices especially braille and they were never trained about these devices. They suggested that for proper implementation of the programme, all stakeholders should get training because even parents need to help their children using these devices at home when doing assignments

\subsection{Theme 4: Large classrooms}

Another challenge that the participants pointed out is large enrollment in the classrooms. They indicated that teaching in an inclusive classroom is challenging. They stated that it prevents teachers from developing close relationship with the learners thus progress is hindered as they are unable to assist the learners who need more attention. They also mentioned that head teachers do not take into consideration the number of children in each classroom, suggested that the learner to teacher ratio must be considered.

Respondents agreed that the reason for learners to behave inappropriately is overcrowding, lack of qualified 
personnel, lack of equipment that may help the learners to learn effectively. They indicated that behavior problem have long been there in regular classrooms. While the teacher is busy with the slow learners (mentally challenged), the gifted learners become bored and start making noise. It also brings back the need for educators to be well equipped with knowledge on how to manage behavior in the classroom.

\subsection{Theme 5: Time allocation}

Participants mentioned that there is no progress in the classroom because one needs more time to explain concepts thoroughly. This shows the importance of creating more time for both the learners and the teacher to make inclusion successful. It also makes it difficult for the teacher to finish the syllabus and to enlarge it, meaning to do extra activities for those with learning difficulties. One participants remarked; "It would be better if the syllabus is developed in such a way that learning difficulties are taken into consideration, making provision for time to give differentiated attention to learners with difficulties the 30 minutes period does not allow us to help learners with disabilities"

\subsection{Theme 6: assessment}

Giving class works and tests is a way of providing feedback about learners' knowledge, skills and attitudes acquired during instruction. Moreover, they are assessed according to what they are capable of doing their progress, abilities and their own potentials. Educators have to assess where learners have difficulty and determine if the learner needs extra help.

Another sub-theme that transpired is that of examination. Respondents mentioned that the centralized education policy is an exclusively one sided policy which is the main cause of discrimination.

"This controversial national exam fails to accommodate learners with diverse needs. It only caters for the gifted, and does not address the needs of learners with disabilities. Mainstream schools at the moment are results driven".

\section{Discussion}

Teachers and head teachers agreed that they experience some challenges in trying to implement inclusive education. Same results were obtained from questionnaires and focus groups. Swart \& Pertipher (2007) say majority of teachers are faced with a difficult task in their classrooms nowadays. These challenges are brought by bringing learners with special needs to regular classrooms where teachers are expected to continue to use the existing curriculum to teach learners who were previously not in the mainstream. The implementation of inclusive education is yet not optimum because of many challenges. For example, the children, parents, and teachers involved in this programme are not ready to participate fully in the programme. So far, those who go to regular schools are those whose intelligence is average and above and ready to participate in regular activities.

Teachers are experiencing the following challenges: lack of teaching and learning materials or resources, lack competencies, large classrooms which are difficult to manage, an environment which is not conducive for the learners with disabilities and that most schools are inaccessible to learners with disabilities. The problem is further compounded by the fact that educators in the mainstream are not trained, the curriculum is inflexible, and teachers are unable to cope with new roles. In addition, there is inadequate parental involvement, lack of relevant human resources, numerous effects of poverty few resource centers: one in the Shiselweni region and one in the Hhohho region. How to assess learners with different levels of abilities is problematic.

When asked if respondents were able to use communicative devices or technological devices, they mentioned that they have never seen some of the materials but theoretically they knew about them but practically not touched them. Educators are to be empowered with skills to make use of the available materials. Inaccessibility to learning materials and educators are some of the contributory factors to learning problems. Pringle (2002) asserts that blind learners are unable to access the curriculum effectively if braille facilities, large prints and other equipment are not available.

Large classes may be viewed as an obstacle to the successful implementation of inclusive education. Westwood (2004) postulates that larger classes place additional demands on the regular educator while reinforcing concern that all students may not receive proper time or attention from the teacher. Van Reusen (2001) says the inclusion of students with disabilities cannot exceed twenty (20) if there is one student with disability in a mainstream class. In some schools it was gathered that there are sixty to seventy pupils in one class. It is true that it is not workable.

Head teachers and teachers agreed with an overwhelming resonation that inclusive education is necessary but 
teachers resent it because of the added workload. Responses from questionnaires showed that teachers have concerns with work load that it will increase. This is similar with what Engelbrecht et al. (2012) says. He states that inclusive education makes an additional demand on teachers especially those in general classes because they are not used to diversity. It is nevertheless the most important suitable route to follow in order to reach the goal of implementing the programme.

Teachers' lack of training makes it impossible for them to supervise teaching and learning in inclusive classrooms. They also agreed with one another that government is not committed to the reforms of inclusive education. One overlooked aspect of inclusion is that it is successful when the teacher receives necessary training. Too often, inclusive education in Swaziland has meant dumping a child with disability into a regular education classroom with little support from teachers as they lack training and development. According to Landsberg (2011) educators who teach learners with barriers to learning require specialized training. The basic professional training such as the entry level, must prepare the educator to respond to a wide range of learners' needs. All educators must be prepared to accommodate diversity among learners and to recognize the need of some learners for alternative instruction.

Educators need to be trained to work with each other as well as other professionals, such as nurses, psychologists, parents and social workers. The results also indicate that schools should be upgraded through staff training so that they are able to respond to the needs of nearby mainstream school. Despite the fact that this was the best move in education that the government of Swaziland has made, introduction of different systems of approach in a short space of time seems to be problematic. These are; the Psychosocial support for those children who need psychological support, spiritual support, emotional support and social support, and individualized education programmes for learners with disabilities. All participants felt it is too much for them to be expected to understand a lot of different concepts and put to them to practice in a very short space of time. Some felt that the Ministry of Education and Training preaches the theory but does not practically demonstrate what they mean. For example, the ministry has not shown how educators can solve the problems they are facing every day.

\section{Conclusion}

It can be concluded that mainstream teachers generally lacked confidence as they attempted to include students with disabilities into classes. This may be the result of lack of training. The importance of the study gives a vivid picture of how the implementation process of inclusive education is processed. There is no progress if there are challenges encountered by educators. These problems lead to negative attitude of the teachers towards the programme.

\section{Recommendations}

The Ministry of Education and Training has to put in place clear educator skills development plan that would address the problem of skills shortage on the part of educators who are already serving in the mainstream schools. Short in-service training courses must be offered to all educators. At least one course on Inclusive Education must be included in all future education studies that are undertaken by prospective teachers in all different tertiary institutions. The in-service staff development should be run over a period of time, with each teacher being required to attend several sessions of it. Lastly, a research needs to be conducted to find out the relationship between knowledge and confidence of teachers teaching learners with disabilities in an inclusive classroom.

\section{References}

Ainscow, M. (2002) Using research to encourage the development of inclusive practices. In: P. Farrell and M. Ainscow (Eds.) Making Special Education Inclusive. London: Fulton.

Ainscow, M. (2009). Psychology for Inclusive Education. New Direction in theory and Practice. London: Routledge.

Ainscow, M. \& Cesar', M. (2006). Inclusive Education, Ten years after Salamanca: Setting the Agenda. European Journal of Psychology of Education. 21 (3)231-238.

Booth, L. (2000). Inclusion and Exclusion: who controls the Agenda Inclusive education. London: David Felton.

Broaderick, A. (2005). Differentiating Instruction for Disabled Students in Inclusive Classrooms. Theory into practice Vol.44:194-202.

Burden, A.(2000). Inclusive education: back to the future with commitment and common sense- case studies. Educare, 29 (1\&2). 28-39.

Department of education. (2005). Draft guidelines for implementation of inclusive education. (First Draft). Pretoria: Department of Education.

Engelbrecht, P, Green, L, Naicher, S., \& Engelbecht, L. (2012). Inclusive Education in Action in South Africa. Pretoria: Van Schaik Publishers. 
Hay, J. F. Smith \& Paulsen, M. (2001). Teacher preparedness in inclusive education. South African Journal of Higher Education, 21 (4) 213- 218.

Kirk, S.A., Gallagher, J.J., Anastasiow, N.J and Coleman, M.R. (2006). Educating Exceptional Children (11th edition). Boston: Houghton. Miffin.

Landsberg, E., Kruger, P, Nel, N. (2006). Addressing Barriers to learning. A Southern African Respective. Pretoria: Van Schaick Publishers.

Landsberg, E. (2011). Addressing Barriers to Learning. A South African Perspective. Pretoria: Van Schaick Publishers.

Landsberg, E., Kruger, D. \& Swart, E. (2011). Addressing barriers to learning: A South African perspective. Second edition. Pretoria: Van Schaik.

Masuku, B. (2010, September 13). Learning Disabilty Forum. The Swazi Observer, p11.

Merriam, S.B. 2002. Qualitative research and case study application in education. San Francisco: Jossey-Bass.

Pringle, H. (2002). Inclusive in Practice. A case study. Paper Presented at 3rd National Learner Support and Development Conference, Kwazulu Natal. 2 October 2002.

Reindal, S.M. (2008). A social relational model of disability: A theoretical framework for special needs education? European Journal of Special Needs Education, 23(2): 135-146.

Swart, E. \& Pettipher, R. (2007). Understanding and Working with Change (eds), Responding to the challenge of Inclusive Education in Southern Africa. Pretoria: Van 121-139

Van Reusen, A. K. (2001). High School teacher attitudes towards Inclusion. The High School Journal 84 (2), 7-17.

Van Zyl, H. (2002). Management strategies for the implementation of an Inclusive education system for learners with Special Educational Needs. Johannesburg: Rand Africans University.

Westwood, P. (2004). Learning and learning difficulties: Approaches to teaching and Assessment. London: David Fulton.

Winter, E.C. (2006). Preparing new teachers for inclusive schools and classrooms. Support for learning 21(2), 85-91. 